\title{
The surgical management of metastatic lesions of the femur
}

\author{
Aaron K Saini, (D) Nando Ferreira* (D) \\ Division of Orthopaedic Surgery, Department of Surgical Sciences, Faculty of Medicine and Health Sciences, Stellenbosch University, \\ Cape Town, South Africa \\ *Corresponding author: nferreira@sun.ac.za
}

Citation: Saini AK, Ferreira N The surgical management of metastatic lesions of the femur. SA Orthop J 2021;20(3):151-156. http://dx.doi.org/10.17159/23098309/2021/v20n3a3

Editor: Dr Thomas Hilton, University of Cape Town, Cape Town, South Africa

Received: August 2020

Accepted: January 2021

Published: August 2021

Copyright: (c) 2021 Saini AK.

This is an open-access article distributed under the terms of the Creative Commons Attribution Licence, which permits unrestricted use, distribution and reproduction in any medium, provided the original author and source are credited.

Funding: No funding was received for this study.

Conflict of interest: The authors declare they have no conflicts of interest that are directly or indirectly related to the research.

\begin{abstract}
Background

Malignant tumours commonly metastasise to bone. When this occurs in the femur, surgical intervention is required to reduce pain and restore mobility post fracture, or as a prophylactic measure when fracture is anticipated. This is typically in the form of replacement with hemi- or total arthroplasty or stabilisation with an intramedullary device. The indications for one modality over the other are debatable and the reported outcomes and complications are varied. The purpose of this study is to assess the management algorithm for bony metastasis of the femur at a tertiary bone tumour unit, and the outcomes of the surgical strategies employed.
\end{abstract}

\section{Methods}

A retrospective cohort study was performed of all patients presenting to our institution with femoral metastasis, both with and without pathological fracture, who were managed surgically from April 2016 to February 2020. Fractures of the femoral neck were managed with cemented arthroplasty. All other fractures were managed with intramedullary nailing, as were all lesions requiring prophylactic stabilisation. Data was recorded regarding demographics, primary pathology, location of lesion, type of surgery, and implant used. The incidence of complications including radiological failure of fixation, infection, thromboembolic phenomena, re-operation and mortality were recorded.

\section{Results}

Eighty-five femurs in 77 patients were included (mean age 61 years, range 20-90). Lesions were located in the femoral neck $(19 / 85,22 \%)$, intertrochanteric $(20 / 85,24 \%)$, subtrochanteric $(40 / 85$, $47 \%)$, diaphyseal $(2 / 85,2 \%)$ and metaphyseal/per-condylar $(4 / 85,5 \%)$ regions of the femur. $A$ total of $64 / 85(753 \%)$ procedures were performed for fractures and $21 / 85(25 \%)$ prophylactically. Eighteen of the $85(21 \%)$ underwent long-stemmed cemented bipolar hemiarthroplasty, 1/85 (1\%) long-stemmed cemented total hip replacement (THR), 62/85 (73\%) cephalomedullary nailing, and $4 / 85(5 \%)$ retrograde femoral intramedullary nailing. Mean follow-up was eight months (range 1-36). There were no dislocations or periprosthetic fractures in the arthroplasty group. One failure $(1 / 66,2 \%)$ of fixation occurred in the intramedullary nailing group. Six deaths occurred in the arthroplasty group $(6 / 64,9 \%)$ and 24 in the nailing group $(24 / 66,36 \%)$ during the study period. Four patients suffered from thromboembolic phenomena $(4 / 77,5 \%)$. Of the 13 patients who sustained a pathological fracture and were managed with intramedullary nailing and followed up for at least one year, all had achieved clinical and radiological union.

\section{Conclusion}

Femoral metastasis can be appropriately managed with intramedullary nailing, both prophylactically and in the event of fracture, with a low rate of implant failure and an expectation that healing will occur once stabilised. Intracapsular fractures can be managed with long-stemmed cemented arthroplasty with a low risk of subsequent fracture or dislocation.

Level of evidence: Level 4

Keywords: bone metastasis, femur, pathological fracture 


\section{Introduction}

Bone is the third most common destination for metastatic disease following the lung and liver. ${ }^{1}$ The occurrence of bone metastasis is associated with a poor prognosis, with five-year survival shown to be between $1 \%$ and $13 \%$ depending on the primary tumour type. ${ }^{2}$ The femur is the most common skeletal site after the ribs and sternum, spine and pelvis, and is the commonest long bone affected. ${ }^{3}$ Surgical intervention may be indicated prophylactically when fracture is anticipated, or after fracture has occurred, to reduce pain and restore function.

Solitary bone metastasis may be amenable to resection with reconstruction. This may offer a chance of cure with complete remission should the primary tumour also be treatable, singularly or through a combination of resection, chemotherapy and radiotherapy.

The Mirels' score is commonly used to estimate the risk of fracture for a given lesion, and can be used in conjunction with clinical assessment, general patient condition, and to guide the surgical intervention. ${ }^{4}$ Post fracture, surgery is typically in the form of stabilisation with an intramedullary device, or replacement with hemi- or total arthroplasty. The indications for one modality over the other are debatable, with a varying range of outcomes shown for each. ${ }^{5-8}$

The purpose of this study is to assess the management algorithm for bony metastasis of the femur at a tertiary bone tumour unit, and the outcomes of the surgical strategies employed.

\section{Methods}

After obtaining Health Research and Ethics Committee approval, we performed a retrospective folder review of all patients presenting to our institution with femoral metastasis, both with and without pathological fracture, who were managed surgically from April 2016 to February 2020 using the algorithm described below.

Patients presenting with lesions without fracture were assessed clinically and radiologically, including a calculation of the Mirels' score, and proceeded to surgical intervention if both patient and surgeon were in agreement. These patients were treated with prophylactic cephalomedullary nail (Figure 1) (Intertan ${ }^{\mathrm{TM}}$, Smith \& Nephew, London, United Kingdom). Patients presenting with fractures of the femoral neck were managed with cemented long-stem Exeter ${ }^{\mathrm{TM}}$ V40 ${ }^{\mathrm{TM}}$ (Stryker, Michigan, USA) bipolar hemiarthroplasty (Figure 1) or total hip replacement (THR) if significant acetabular disease was identified. All inter/subtrochanteric (Figure 2) and diaphyseal fractures (Figure 3) were managed with cephalomedullary nail (Intertan ${ }^{\mathrm{TM}}$ Smith \& Nephew), and metaphyseal/per-condylar fractures with the Metatan $^{\mathrm{TM}}$ retrograde femoral nail (Smith \& Nephew).

Post surgery, patients received bisphosphonates, and once all wounds had healed, all patients received radiotherapy. Chemo/ hormonal therapy was instituted by the medical oncology team if indicated. This varied depending on primary, subtype, and patient appropriateness, including comorbidities and prognosis.
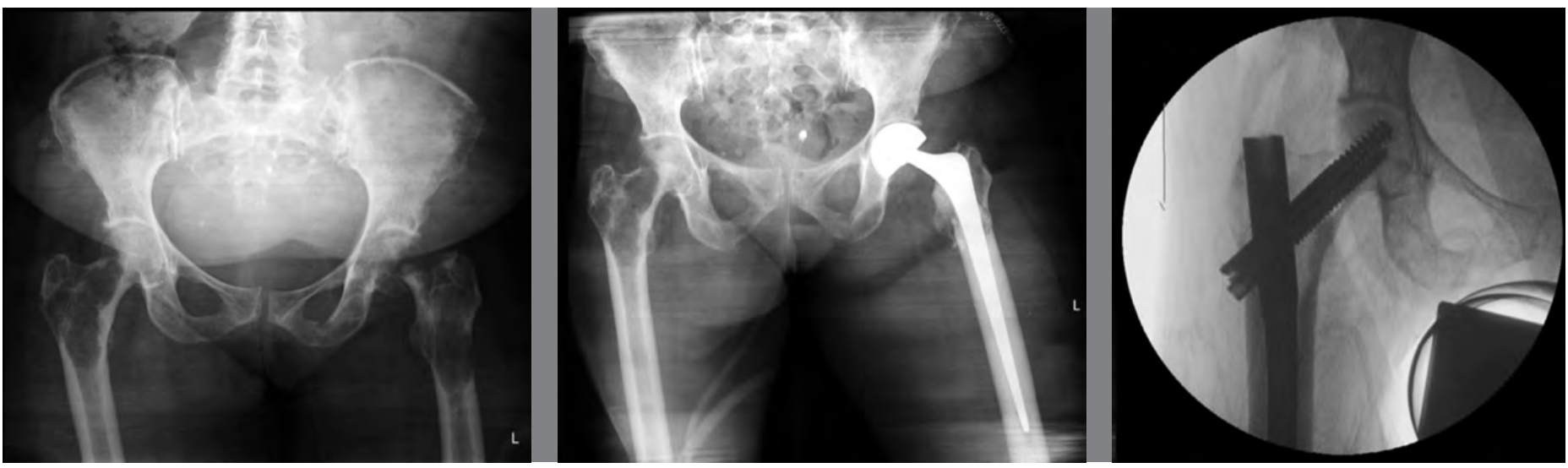

Figure 1. A 62-year-old patient with metastatic breast cancer who sustained a left femoral neck fracture managed with long-stemmed cemented hemiarthroplasty. The patient subsequently underwent right prophylactic cephalomedullary nailing. Radiographs pre- and post-hemiarthroplasty and cephalomedullary nailing
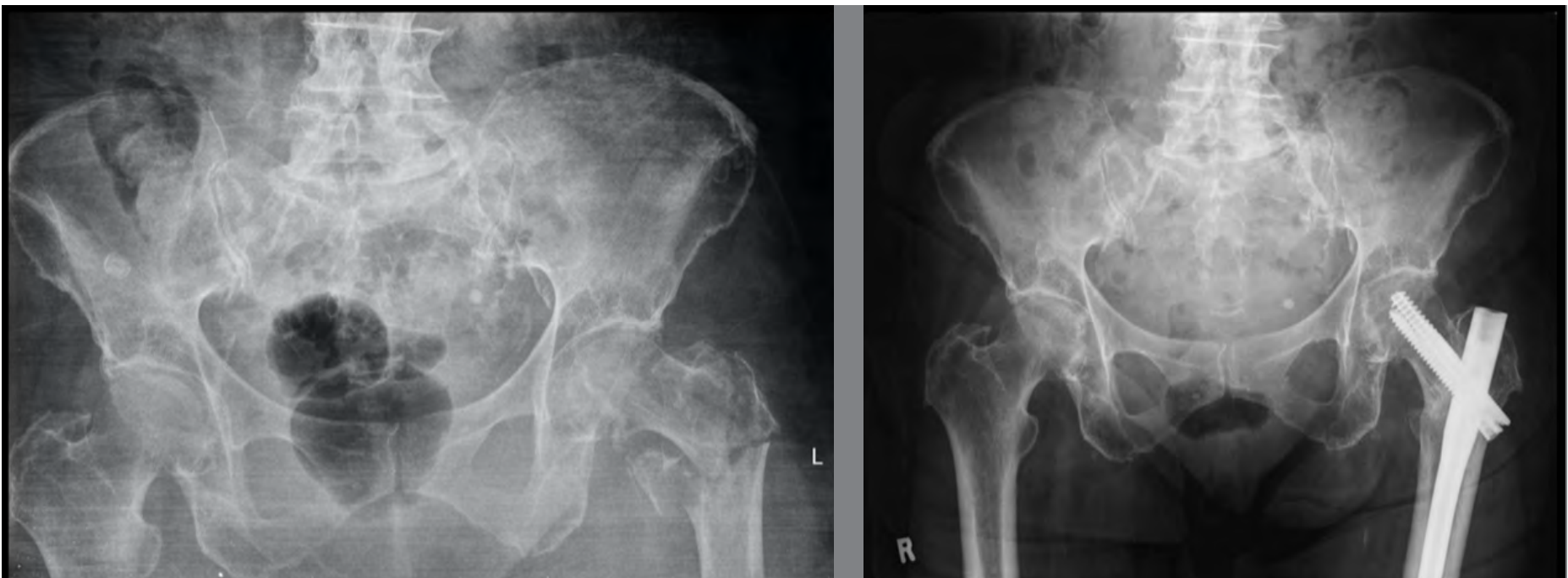

Figure 2. An 83-year-old patient with metastatic breast cancer who sustained a left intertrochanteric femoral fracture. Radiographs pre- and one-year postcephalomedullary nailing 




Figure 3. A 68-year-old patient with metastatic breast cancer who sustained a left diaphyseal femoral fracture. Radiographs pre- and postcephalomedullary nailing

Data was recorded regarding demographics, primary pathology, location of lesion, type of surgery and implant used. The incidence of complications including radiological failure of fixation, infection, thromboembolic phenomena, re-operation, and mortality were recorded. Mortality was considered perioperative if within 48 hours of the procedure, early postoperative if within one month, or late if after one month. Patients with incomplete records were excluded.

\section{Results}

The final cohort consisted of 58 female patients (75\%) and 19 male patients $(25 \%)$ with a mean age of 61.6 years, (range $20-90$ ) (Table I). Mean follow-up was 8.3 \pm 8.52 SD months (range 1-36). A total of 85 femurs in 77 patients underwent surgical management (Tables II and III).

No dislocations or periprosthetic fractures were seen in patients who received arthroplasty. One failure of fixation occurred in the retrograde intramedullary group $(1 / 4,25 \%)$ two months post procedure. The patient was deemed to be medically unfit for revision surgery and died two months post failure. There were no failures in the cephalomedullary group, giving an overall failure rate for the nailing group of $1 / 66(2 \%)$.

Six patients who underwent an arthroplasty procedure demised

Table I: General characteristics of included participants

\begin{tabular}{lc} 
& $\mathrm{n}=77$ \\
Age (mean \pm SD, years) & $61.6 \pm 12.32(77)$ \\
\hline Sex & \\
$\quad$ Female & $75.3 \%(58)$ \\
$\quad$ Male & $24.7 \%(19)$ \\
\hline Side & \\
Left & $48.1 \%(37)$ \\
Right & $41.6 \%(32)$ \\
Bilateral & $10.4 \%(8)$ \\
\hline Follow-up (months) & $8.3 \pm 8.52$ SD (77)
\end{tabular}

Data is presented as mean \pm standard deviation and frequencies, with the number of participants in parentheses. during the study period (6/19, 32\%); one early postoperative and five deemed late, at a mean of four months post procedure. The early death occurred in a patient who was readmitted 13 days post procedure with respiratory compromise and a pericardial effusion. Cardiac arrest and death occurred within 24 hours of readmission.

Among patients who underwent intramedullary nail fixation, 24 deaths $(24 / 66,36 \%)$ occurred during the study period: one perioperative, one early postoperative, and 22 late, at a mean of 9.3 months post surgery. The single perioperative mortality occurred in a patient who underwent sequential humeral followed by femoral intramedullary nailing during a single sitting and subsequently suffered on-table cardiac arrest. The patient was resuscitated but died 24 hours thereafter. Post-mortem examination was unable to provide a definite cause of death, but note was made of bone marrow emboli within the lungs. The early postoperative death occurred in a patient who was readmitted 14 days post procedure with a superficial wound infection. After consultation with the anaesthetic team, the patient was felt to be inappropriate for further surgical intervention and was managed with systemic antibiotics. The patient developed an acute abdomen 22 days following surgery but the general surgical team felt surgical intervention to be inappropriate. The patient died 23 days post surgery.

Four patients suffered thromboembolic phenomena in the early postoperative period $(4 / 77,5 \%)$. All had been receiving weightadjusted chemical thromboprophylaxis in the form of low molecular weight heparin $(\mathrm{LMWH})$. One patient in the arthroplasty group developed a proximal deep vein thrombosis (DVT). In the nailing group, two patients developed pulmonary emboli, and one patient a proximal DVT. All were anti-coagulated initially with treatmentdose LMWH followed by Warfarin.

Of the patients who sustained a pathological fracture managed with intramedullary nailing, 13 were followed up for at least one year. All 13 of these had achieved clinical and radiological bony union at the one-year mark.

\section{Discussion}

The management of metastatic disease of the femur remains controversial in terms of implant choice in relation to the location and extent of the lesion. The aim of this study was to review our current management algorithm for femoral metastatic lesions.

Cephalomedullary fixation is generally performed for extracapsular proximal femur lesions, either prophylactically or post fracture. Variation exists in the outcomes and recommendations in the literature. Wedin and Bauer ${ }^{9}$ suggested that for fractures of the proximal third of the femur, endoprosthetic replacement was preferable to reconstruction nailing due to lower implant failure rates ( $8.3 \%$ vs $13.6 \%$ respectively). A large study of 228 implanted nails ${ }^{10}$ recorded an implant failure rate of $8 \%$, with those implanted for fracture failing at a higher rate than those inserted prophylactically (hazard risk 3.61). We did not observe any instances of implant failure in our series. Another study reported a 'loss of implant stability in 19 of $199(10 \%)$ ' of peritrochanteric lesions treated with cephalomedullary nails. ${ }^{11}$ Nails were inserted both prophylactically and for the treatment of fractures, although the proportions performed for each was not stated. The reasons for the loss of stability included fracture, disease progression, non-union and implant failure. Fifty-one per cent of the procedures included curettage of the metastatic deposit with cement augmentation. No cement augmentation was used in our series as we encountered no cases where it was deemed necessary. Our single loss of fixation occurred in a patient who underwent retrograde nailing for a very distal metaphyseal fracture.

Traditional teaching has often suggested that pathological fractures secondary to malignancy have variable potential to heal. Of our patient cohort who were reviewed clinically and 
Table II: Summary of primary pathology and treatment

\begin{tabular}{lc} 
& $\%(\mathrm{n})$ \\
Primary pathology $(\mathrm{n}=77)$ & $58(45)$ \\
Breast & $16(12)$ \\
Lung & $10(8)$ \\
Prostate & $9(7)$ \\
Haematological & $4(3)$ \\
Renal & $1(1)$ \\
Gastric & $1(1)$ \\
Rectal & \\
\hline Anatomical location of lesion $(\mathrm{n}=85)$ & $22(19)$ \\
Femur neck & $24(20)$ \\
Intertrochanteric & $47(40)$ \\
Subtrochanteric & $2(2)$ \\
Diaphyseal & $5(4)$ \\
Distal metaphysis & \\
\hline Surgical procedures & $53 \%(45)$ \\
Fracture fixation & $25 \%(21)$ \\
Prophylactic fixation & $22 \%(19)$ \\
Arthroplasty &
\end{tabular}

Data is presented as frequencies, with the number of participants in parentheses.

radiologically at one year, while small at 13 patients, all achieved union. Gainor and Buchert ${ }^{12}$ showed an overall union rate of $35 \%$ in 129 patients with fractures (not confined to the femur), although wide variation existed depending on the primary type, method of stabilisation, subsequent lifespan of the patient, and the dose of postoperative radiotherapy applied. Our high rate of union would suggest that despite the bone being pathological, it retains healing potential when provided with stability and an appropriate mechanical environment.

Surgery of the lower limbs and malignancy are independent risk factors for thromboembolic phenomenon. Venous thromboembolism is six times more prevalent in cancer patients and is the second largest cause of death in this patient group. ${ }^{13}$ Aneja et al. ${ }^{14}$ suggested that femoral metastases treated prophylactically were more likely than those treated post fracture to develop pulmonary emboli and DVT (odds ratio 2.1 and 1.5 respectively). We did not find such a disparity, with thromboembolic phenomena seen in $4.8 \%$ of the prophylactic group vs $5.4 \%$ of those treated post fracture. Our overall rate of $5 \%$ was slightly lower than that of other studies of surgically managed long-bone metastasis which found rates between $6 \%$ and $10 \% .{ }^{15-17}$ It is worth noting that the patients in each of these study groups received varying levels of perioperative chemo-thromboprophylaxis. The four cases of thromboembolism in our series were observed in patients who had been receiving weight-adjusted chemical thromboprophylaxis in the form of LMWH, as did our entire cohort.

Long-stemmed cemented arthroplasty has an established role in complex primary and revision arthroplasty. Its use in the context of femoral metastatic disease has a hypothetical but logical benefit over shorter stems in terms of protecting a longer segment of femur. This is from the possibility of future periprosthetic fracture of known, occult or new femoral metastatic deposits. Good results were reported by Peterson et al. ${ }^{18}$ in their series of 21 patents who underwent cemented long-stem hemiarthroplasty for metastatic disease with either impending or fractured proximal lesions; one periprosthetic fracture occurred three months post procedure, with no dislocations or infections. Similarly, Randall et al. ${ }^{19}$ reported one periprosthetic fracture in 27 patients, one haematoma requiring evacuation, but no dislocations or infections. We did not observe any periprosthetic fractures, dislocations or infections in the current series.

Bone cement implantation syndrome is a recognised phenomenon occurring in cemented hemi- and total arthroplasty of the hip. There is wide variation in the precise definition, incidence and effect on intra- and perioperative mortality. ${ }^{20-22}$ Risk stratification is generally described based on the American Society of Anesthesiologist's Physical Status classification (ASA-PS). Metastatic disease has a wide variation in associated functional and physiological impairment, and as a diagnosis in itself does not relate to a patient's ASA-PS. However, Herrenbruk et al. ${ }^{23}$ showed a statically significant increase in the risk of cement-associated complications in patients with metastatic disease undergoing long-stem cemented hemiarthroplasty when compared with those that did not. Randall et al. ${ }^{19}$ described their strategy of reducing cement-related complications, including aggressive medullary lavage, canal suctioning, the use of early low-viscosity cement and slow, controlled insertion of the long stem. Cement-related hypotension occurred in $14 \%$ of their series, with no cardiac events or deaths. Petersen et al. ${ }^{18}$ in their series of 21 patents recorded no cemented-related complications; this was also the case in our series.

Mega-prosthetic replacement has an established role in the management of metastatic bone lesions. This is usually reserved for cases where reconstruction post fracture, or for prophylaxis, using intramedullary nails or conventional arthroplasty is felt unlikely to succeed given the location and extent of a metastatic lesion. We agree with their use in specific cases but did not encounter any we felt required this in our series.

Simultaneous nailing of long bones in the context of metastatic disease has a significant mortality. Ristevski et al. ${ }^{24}$ reported $3 / 18(17 \%)$ of patients in their series of simultaneous bilateral femoral nailing died intraoperatively. Moon el al. ${ }^{25}$ in their series of simultaneous nailing which included combinations of femurs, humeri and a tibia, reported two mortalities in their series of 16 patients as a direct result of acute pulmonary complications secondary to simultaneous nailing. One of these occurred intraoperatively. Our only on-table cardiac arrest occurred in the only patient in our series undergoing sequential nailing of two long

Table III: Summary of treatment complications

\begin{tabular}{lcc} 
Locale of lesion $(\mathrm{n})$ & Procedure & Complications \\
\hline Femur neck (19) & $\begin{array}{c}\text { Cemented bipolar hemiarthroplasty (18) } \\
\text { Cemented total hip arthroplasty (1) }\end{array}$ & $\begin{array}{c}\text { None } \\
\text { None }\end{array}$ \\
\hline Intertrochanteric (20) & $\begin{array}{c}\text { Cephalomedullary nail (20) } \\
\text { (fracture 13, prophylactic 7) }\end{array}$ & None \\
\hline Subtrochanteric (40) & $\begin{array}{c}\text { Cephalomedullary nail (40) } \\
\text { (fracture 26, prophylactic 14) }\end{array}$ & None \\
\hline Diaphyseal (2) & $\begin{array}{c}\text { Cephalomedullary nail (2) } \\
\text { (both for fracture) }\end{array}$ & None \\
\hline Distal metaphysis (4) & $\begin{array}{c}\text { Retrograde femur nail (4) } \\
\text { (all for fracture) }\end{array}$ & Fixation failure (1) \\
\hline
\end{tabular}

Data is presented as the number of participants in parentheses. 
bones (a femur and humerus) in one session, with death occurring within 24 hours. This supports the need for the staging of the required procedures when prophylactic, which we now perform at our institution at an interval of four to six weeks.

Our management algorithm for the surgical management of femoral metastasis consisting of cemented long-stemmed arthroplasty for neck fractures, and intramedullary nailing for all other fractures and prophylaxis, leads to favourable outcomes. We observed no periprosthetic fractures, dislocations, bone cement reactions or infections in the arthroplasty group. In the nailing group, we saw no implant failures and a single loss of fixation. Thromboembolic phenomena occurred at a rate slightly lower than the published literature in the context of all of our patients receiving chemical prophylaxis. Caution should remain regarding sequential nailing of long bones; the only perioperative death occurred after this was performed on a patient's femur and humerus.

The main limitation in our series is that of frequency and duration of follow-up. The cause of this can be attributed to two factors. First, the position of our service as a tertiary referral centre for an entire province means that patients are often faced with extended journeys from rural areas. This may include journeys to regional hospitals followed by overnight transfer to our centre, meaning that patients will often only attend when in difficulty. The second factor is the poor prognosis of the cohort, namely patients with bone metastasis from disseminated malignancy. One-year survivorship for patients with metastatic lesions of the femur treated surgically has been reported at between $14 \%$ and $35 \% .{ }^{11,26}$ This high mortality unavoidably reduces the duration and number of patients that can be followed up.

\section{Conclusion}

Femoral metastasis can be managed with intramedullary nailing, both prophylactically and in the event of fracture, with an expectation that healing will occur once stabilised. Intracapsular fractures can be managed with long-stemmed cemented hemiarthroplasty with a low risk of subsequent fracture or dislocation.

\section{Ethics statement}

The authors declare that this submission is in accordance with the principles laid down by the Responsible Research Publication Position Statements as developed at the 2nd World Conference on Research Integrity in Singapore, 2010.

Ethical approval for this study was obtained prior to commencement of data collection: Health Research Ethics Committee, Stellenbosch University, ethics reference number N20/04/042

All procedures were in accordance with the ethical standards of the responsible committee on human experimentation (institutional and national) and with the Helsinki Declaration of 1975, as revised in 2008.

\section{Declaration}

The authors declare authorship of this article and that they have followed sound scientific research practice. This research is original and does not transgress plagiarism policies.

\section{Author contributions}

AKS: Study conceptualisation, acquisition, analysis and interpretation of data, first draft preparation, revision and submission of the final manuscript

NF: Study conceptualisation, acquisition, analysis and interpretation of data, revision of manuscript and approval of final draft

\section{ORCID}

Saini AK (iD https://orcid.org/0000-0002-2661-8445

Ferreira N (D) https://orcid.org/0000-0002-0567-3373

\section{References}

1. Macedo F, Ladeira K, Pinho F, et al. Bone metastases: an overview. Oncol Rev. 2017;11(1):321. https://doi.org/10.4081/oncol.2017.321.
2. Svensson E, Christiansen CF, Ulrichsen SP, et al. Survival after bone metastasis by primary cancer type: A Danish population-based cohort study. BMJ Open. 2017 Sep 11;7(9):e016022.

3. Kakhki VR, Anvari K, Sadeghi R, et al. Pattern and distribution of bone metastases in common malignant tumors. Nucl Med Rev Cent East Eur. 2013;16(2):66-69. https://doi.org/10.5603/nmr.2013.0037.

4. Mirels $\mathrm{H}$. Metastatic disease in long bones. A proposed scoring system for diagnosing impending pathologic fractures. Clin Orthop Relat Res [Internet]. 1989;249:256-64. Available from: https://www.ncbi.nlm.nih.gov/ pubmed/2684463.

5. Siegel GW, Biermann JS, Calinescu AA, et al. Surgical approach to bone metastases. Curr Osteoporos Rep. 2018;16(4):512-18. https://doi.org/10.1007/ s11914-018-0463-7.

6. Soeharno H, Povegliano L, Choong PF. Multimodal treatment of bone metastasis-a surgical perspective. Front Endocrinol. 2018;9:518. https://doi. org/10.3389/fendo.2018.00518.

7. Damron TA, Sim FH. Surgical treatment for metastatic disease of the pelvis and the proximal end of the femur. Instr Course Lect [Internet]. 2000;49:46170. Available from: https://www.ncbi.nlm.nih.gov/pubmed/10829199.

8. Jonas SC, Mehendale SM, Bick SM, Baker RP. Current orthopaedic management of bony metastases in the proximal third of the femur. Hip Int. 2017;27(1):1-7. https://doi.org/10.5301\%2Fhipint.5000497.

9. Wedin R, Bauer HC. Surgical treatment of skeletal metastatic lesions of the proximal femur: endoprosthesis or reconstruction nail? J Bone Jt Surg Br. 2005;87(12):1653-57. https://doi.org/10.1302/0301-620x.87b12.16629.

10. Willeumier JJ, Kaynak M, Van der Zwaal P, et al. What factors are associated with implant breakage and revision after intramedullary nailing for femoral metastases? Clin Orthop Relat Res. 2018;476(9):1823-33. https://doi. org/10.1007/s11999.0000000000000201.

11. Chafey DH, Lewis VO, Satcher RL, Moon BS, Lin PP. Is a cephalomedullary nail durable treatment for patients with metastatic peritrochanteric disease? Clin Orthop Relat Res. 2018;476(12):2392-401. https://doi.org/10.1097/ corr.0000000000000523.

12. Gainor BJ, Buchert P. Fracture healing in metastatic bone disease. Clin Orthop Relat Res [Internet]. 1983;178:297-302. Available from: https://www.ncbi.nlm. nih.gov/pubmed/6883864.

13. Donnellan E, Khorana AA. Cancer and venous thromboembolic disease: a review. Oncologist. 2017;22(2):199-207. https://doi.org/10.1634/ theoncologist.2016-0214

14. Aneja A, Jiang JJ, Cohen-Rosenblum A, et al. thromboembolic disease in patients with metastatic femoral lesions: a comparison between prophylactic fixation and fracture fixation. J Bone Jt Surg Am. 2017;99(4):315-23. https://doi. org/10.2106/jbjs.16.00023.

15. Groot $\mathrm{OQ}$, Ogink PT, Janssen SJ, et al. High risk of venous thromboembolism after surgery for long bone metastases: a retrospective study of 682 patients. Clin Orthop Relat Res. 2018;476(10):2052-61. https://doi.org/10.1097/corr.00 00000000000463

16. Ratasvuori M, Lassila R, Laitinen $M$. Venous thromboembolism after surgical treatment of non-spinal skeletal metastases - An underdiagnosed complication. Thromb Res. 2016;141:124-28. https://doi.org/10.1016/j.thromres.2016.03.013.

17. Shallop B, Starks A, Greenbaum S, et al. Thromboembolism after intramedullary nailing for metastatic bone lesions. J Bone Jt Surg Am. 2015;97(18):1503-11. https://doi.org/10.2106/jbjs.n.01067.

18. Peterson JR, Decilveo AP, O'Connor IT, et al. What are the functional results and complications with long stem hemiarthroplasty in patients with metastases to the proximal femur? Clin Orthop Relat Res. 2017;475(3):745-56. https://doi. org/10.1007/s11999-016-4810-7.

19. Randall RL, Aoki SK, Olson PR, Bott SI. Complications of cemented long-stem hip arthroplasties in metastatic bone disease. Clin Orthop Relat Res. 2006;443: 287-95. https://doi.org/10.1097/01.blo.0000191270.50033.3a.

20. Costa ML, Griffin XL, Pendleton N, Pearson M, Parsons N. Does cementing the femoral component increase the risk of peri-operative mortality for patients having replacement surgery for a fracture of the neck of femur? Data from the National Hip Fracture Database. J Bone Jt Surg Br. 2011;93(10):1405-10. https://doi.org/10.1302/0301-620x.93b10.26690.

21. Donaldson AJ, Thomson HE, Harper NJ, Kenny NW. Bone cement implantation syndrome. Br J Anaesth. 2009;102(1):12-22. https://doi.org/10.1093/bja/aen3 28.

22. Talsnes O, Vinje T, Gjertsen JE, et al. Perioperative mortality in hip fracture patients treated with cemented and uncemented hemiprosthesis: a register study of 11,210 patients. Int Orthop. 2013;37(6):1135-40. https://doi.org/10.100 7\%2Fs00264-013-1851-3.

23. Herrenbruck T, Erickson EW, Damron TA, Heiner J. Adverse clinical events during cemented long-stem femoral arthroplasty. Clin Orthop Relat Res. 2002;(395):154-63. https://doi.org/10.1097/00003086-200202000-00017.

24. Ristevski B, Jenkinson RJ, Stephen DJ, et al. Mortality and complications following stabilization of femoral metastatic lesions: a population-based study 
of regional variation and outcome. Can J Surg [Internet]. 2009;52(4):302-308.

Available from: https://www.ncbi.nlm.nih.gov/pubmed/19680515.

25. Moon B, Lin P, Satcher R, Lewis V. Simultaneous nailing of skeletal metastases: is the mortality really that high? Clin Orthop Relat Res 2011;469(8):2367-70. https://doi.org/10.1007/s11999-011-1814-1.

26. Sarahrudi K, Hora K, Heinz T, et al. Treatment results of pathological fractures of the long bones: a retrospective analysis of 88 patients. Int Orthop. 2006;30(6):519-24. https://doi.org/10.1007/s00264-006-0205-9. 